\title{
LA POÉTICA DE ARISTÓTELES Y LA RELECTURA DE JOHN HENRY NEWMAN Rosario Athié*
}

RESUMEN: En este texto se analiza la relectura de John Henry Newman a la Poética de Aristóteles, con el objetivo de abordar el pensamiento de Newman desde una de sus principales fuentes: el pensamiento aristotélico.

PALABRAS CLAVE: John Henry Newman, Aristóteles, poética, poesía.
ARISTOTLE'S POETICS AND THE RE-READING OF JOHN HENRY NEWMAN

ABSTRACT: This text analyzes John Henry Newman's re-reading of Aristotle's Poetics, with the aim of approaching Newman's thought from one of its key sources: Aristotelian thought.

KeYwORDS: John Henry Newman, Aristotle, Poetics, Poetry.

RECEPCIÓN: 25 de noviembre de 2016.

ACEPTACIÓN: 9 de diciembre de 2016.

* Universidad Panamericana, Guadalajara. 


\author{
LA POÉTICA DE ARISTÓTELES \\ Y LA RELECTURA DE \\ JOHN HENRY NEWMAN
}

\title{
Introducción y contexto
}

Abordar el pensamiento de John Henry Newman (1801-1890) desde una de sus fuentes clave, Aristóteles, ha resultado una tarea realmente gratificante. En esta ocasión, expondré el comentario que Newman escribió sobre la Poética, escrita por Aristóteles entre los años 335 y 323 a.C., a manera de apuntes de clase. De esta obra solo se conserva la primera parte, que versa sobre la tragedia y la epopeya, donde define y caracteriza la tragedia y otras artes imitativas, por lo que se detiene en el tema de la mimesis; al parecer se ha perdido la segunda parte. Tal elección por parte de Newman muestra el interés por el
Filósofo en aquella época en la Universidad de Oxford.

Newman vivió casi todo el siglo XIX, por lo que fue contemporáneo de momentos históricos de Gran Bretaña, como la victoria sobre Napoleón, la expansión del Imperio Británico, el desarrollo de las ciencias empíricas, la pujante época de la Reina Victoria... Igualmente, Newman fue receptor de una larga tradición cultural y académica que abarca los vestigios del mundo romano en la Isla Británica veinte siglos antes, así como la tradición cristiana impulsada por medio de la educación de monjes benedictinos que, conducidos por Agustín, 
arribaron hacia el año 596 bajo el impulso del papa Gregorio Magno. La educación que impartieron los benedictinos en la isla estaba basada en el dominio del latín y el griego, la literatura clásica y la propia lengua, la música y las matemáticas. Esta impronta benedictina quedó plasmada en las instituciones educativas británicas, como la Universidad de Oxford, a la que me voy a referir.

Como sabemos, los escritos de Aristóteles se perdieron en Europa más de diez siglos, hasta que fueron redescubiertos gracias a los árabes y los judíos, quienes facilitaron la difusión de estos textos en las nacientes universidades.

En el siglo XIII, Roger Bacon (1214-1292) estudió a Aristóteles en la Universidad de Oxford y profundizó en sus escritos con verdadero entusiasmo. Después de graduarse como maestro en artes liberales, fue uno de los primeros profesores que enseñó las obras de Aristóteles sobre filosofia natural y metafísica. Más tarde, en la década de 1240, Bacon trabajó en la Universidad de París, donde transmitió a sus alumnos esta misma admiración. Llegó a establecer su propio método en la investigación científico-experimental influido por el Filósofo. Bacon también reformó el sistema de estudios filosóficos y teológicos, y además de la academia de lengua, incorporó la academia de ciencia, que hasta entonces no existía en las demás universidades. Hacia el final de su vida, Bacon regresó a Oxford, donde también ejerció esta influencia, que quedó plasmada en un estilo de investigación y una forma de educar que ha promovido desde entonces tanto las letras como las ciencias. El empirismo inglés deriva, en parte, de las reflexiones de Bacon inspiradas en Aristóteles.

Desde la primera mitad del siglo XIX, en el que vivió Newman, el aristotelismo tomó fuerza en Oxford. Encontramos un destacado interés por Aristóteles en el Oriel College, donde se había reunido un grupo de filósofos teólogos anglicanos llamados "noéticos". En ese tiempo abundaron las publicaciones referidas a Aristóteles, con traducciones, ediciones y notas estudiantiles sobre retórica, que expresan un movimiento pedagógico con una tradición ampliamente humanista. Entre los destacados autores que se relacionaron con Newman están Edward Copleston, Richard Whately y el primer ministro Gladstone.

John Henry Newman estudio en el Trinity College de 1817 a 1822 . La vasta cultura que adquirió en aquellos años, el dominio del latín y el griego, le abrieron las puertas a los textos originales de grandes autores. De Aristóteles, Newman estudió principalmente las obras que podrían considerarse dentro de la filosofía 
práctica, como la Ética, la Lógica y la Poética. Al lector de Aristóteles le es fácil reconocer, en la lectura de Newman, la influencia del autor clásico. La huella que dejó en aquel joven fue sobre todo una perspectiva epistemológica, el hábito filosófico, las actitudes y puntos de vista que "reflejan directamente sus preocupaciones teóricas y más vitales". ${ }^{1}$ Estas características ofrecen el sello de un verdadero aristotelismo, y pueden también considerarse como requisitos para la reflexión filosófica.

En este tenor, quisiera destacar algunas de estas características del pensamiento aristotélico que Newman hizo propias. En primer lugar, "un gran sentido de lo concreto y de fundamentación en lo real". ${ }^{2}$ Es quizá este punto una de las más destacadas notas del pensamiento no solo de Newman, sino en general del ambiente intelectual inglés, que él mantuvo a pesar del empirismo de tendencia inmanentista. A Aristóteles lo caracteriza también el "amor absoluto por la verdad, por el conocimiento de la realidad en todos sus reinos y estratos; y la sujeción a la verdad, dondequiera que ella se encuentre", a lo que Newman añadía: "sin importar adónde me lleve". Tal "honestidad intelectual" supuso para ambos tanto "la veraci-

\footnotetext{
${ }^{1}$ Rómulo Ramírez Daza y García, "Aristóteles, el Filósofo", Sincronía, 2016, XX, núm. 70, p. 11. ${ }^{2}$ Ibid., p. 12.
}

dad en el decir, como la alta sinceridad" entre su pensamiento y su palabra, así como "la grave coherencia ética entre vida y pensamiento", 3 porque todas sus potencias están dirigidas a la verdad, de manera que su "percepción, voluntad e inteligencia siempre están de cara a lo real, esto es, sus facultades inferiores y superiores". ${ }^{4}$ Con perfecto dominio de sí, sus capacidades quedan sumadas en el único objetivo de servir siempre a la verdad.

En segundo lugar, Newman aprendió de Aristóteles "un espíritu siembre abierto a la observación de nuevos datos y fenómenos", que se une a "la actitud de replanteamiento constante de los problemas y el afán de precisión en el lenguaje". Podemos notar al respecto la tendencia de Newman, y en general en su época, a escribir "ensayos", abiertos a la reconsideración, lo que implica "la inclusión positiva de la crítica, tanto propia como externa en pro de la verdad". 5

En tercer lugar, el aristotelismo en Newman se manifiesta en la armonía entre lo que se ha recibido y lo que se descubre. "El reconocimiento del valor de la tradición" llevó a este autor lo mismo a explorar las realidades desde sus orígenes, que a descubrimientos insospechados para el tiempo

\footnotetext{
${ }^{3}$ Loc. cit.

${ }^{4}$ Ibid., p. 14.

${ }^{5}$ Ibid., p. 12.
} 
que le correspondió vivir, gracias al "profundo asombro y respeto por la naturaleza"6 de las cosas y de la realidad humana, así como de su sentido. Tal formación intelectual, recibida en el Trinity College, inculcó en el joven Newman la capacidad reflexiva que le sirvió para forjar su propio pensamiento. A los 21 años, sus reflexiones ya eran originales, gracias a lo cual fue aceptado en el famoso Common Room de profesores de Oriel College y comenzó a colaborar con Richard Whately, con el que publicó textos como Elements of Logic. Con perspectiva histórica, Newman es considerado un pensador original en los ámbitos teológico, filosófico, histórico, educativo y, sin lugar a dudas, se le reconoce como un escritor clásico de la lengua inglesa, tanto en prosa como en verso.

\section{La Poética de Aristóteles y la relectura de Newman Antecedentes}

En 1827, Newman fue invitado a publicar su primera obra como autor principal. Eligió entonces la Poética de Aristóteles, para dar a conocer sus comentarios sobre aquel a quien consideraba el más grande de los filósofos analíticos. El resultado fue un artículo para la revista The London

\footnotetext{
${ }^{6}$ Loc. cit.
}

Review a manera de ensayo, que tituló "Poetry with reference to Aristotle's Poetics".?

Ian Ker, uno de sus biógrafos, anota lo siguiente:

A finales de septiembre [de 1827], Newman comenzó a escribir un ensayo que consideraría poco más que un artículo efímero, encargado por un colega para un periódico nuevo. Era un ejemplo de crítica literaria de finales de la época romántica a principios de la victoriana; su autor se habría sorprendido al conocer la actual atención que se ha prestado a este tipo de escritos. "Poesía, que evoca a la Poética de Aristóteles", lo terminó en octubre y fue publicado el siguiente mes de enero en la London Review, de breve duración, editada por Joseph Blanco White, miembro del Common Room de Oriel, que estaba ordenado en el anglicanismo pero tenía la novedosa distinción de ser un exsacerdote católico de España, aunque de ascendencia irlandesa.

Newman criticaba el énfasis de Aristóteles en la importancia de la trama, argumentando que la tragedia griega, de hecho, se distinguía por

${ }^{7}$ Para la ubicación actual del texto, conviene saber que Newman, siendo mayor, en 1871, revisó la colección de ensayos que había publicado previamente de manera dispersa y los reunió bajo el título Essays critical and historical. Este trabajo sobre Aristóteles lo colocó en el primer volumen y aparece el primero en dicha colección. Hoy día es posible acceder al texto original en $<$ www. newmanreader.org>. 
su caracterización y poesía, no por su acción. Él platonizó la definición aristotélica de poesía como "una representación de lo ideal", e insistió en que "la condición de una mente poética" no es solo un "verdadero estado moral del corazón”, sino que había una "conexión entre el querer de un principio religioso y el querer de un sentimiento poético". Aceptaba el corolario de que "la Religión revelada debería ser especialmente poética" y que "una visión poética de las cosas" era una tarea propiamente cristiana. El lenguaje de la poesía es "un simple accesorio al talento poético" y "aunque indispensable para su exposición, no es una parte esencial de la poesía", de modo que "la atención al lenguaje en sí mismo es prueba del simple artista, no del verdadero poeta". 8

Años más tarde, en The idea of a university, Newman superó esta dicotomía entre el contenido y la forma proponiendo una definición clásica del estilo literario, que contradice lo que había escrito siendo joven: "El pensamiento y el discurso son inseparables el uno del otro [...] el estilo es un pensamiento expresado a través de la lengua".

${ }^{8}$ Ian Ker, John Henry Newman: Una biografia, 2010, Madrid, Palabra, p. 54. Las citas dentro del texto hacen referencia a John Henry Newman, Essays critical and historical I, pp. 9, 21-25.

${ }^{9}$ John Henry Newman, The idea of a university, 1976, Oxford, Parte 1, p. 232. Véase Goeffrey y

\section{Contenido del ensayo}

Newman dedica el primer párrafo de su ensayo a resumir los puntos tratados por Aristóteles en la Poética, tomando las siguientes afirmaciones de Aristóteles: la excelencia de una tragedia depende de su trama; la tragedia, como tal, es la exposición de una acción abstraída, no real. En función a ello, Newman destaca que Aristóteles pone especial atención en la economía de la fábula, entendiendo por economía el mejor uso de los recursos lingüísticos para el logro de un resultado más adecuado. Dice que en función a esta "economía" se determina la gama de temas, se delinean sus proporciones, se traza su evolución desde el nudo de la trama hasta su desenlace, se investigan los medios para lograr introducir acontecimientos sorprendentes o impactantes y se muestra cómo la exposición del carácter de los personajes queda subordinada al propósito de la acción.

A continuación me referiré a las cinco tesis que he extraído de Newman.

\section{Primera tesis}

La tesis central del ensayo consiste en observar que, si bien Aristóteles hace un estudio científico para deter-

Kathleen Tilloston, Mid-Victorian studies, 1965 , Londres, pp. 256-257. 
minar las reglas literarias, Newman concluye que la intención del Filósofo era dejar claro que no hay por qué esperar que la tragedia siga estrictamente las normas científicas para lograr la mayor calidad, porque sigue siendo excelsa una tragedia sin tener que caer bajo las rígidas leyes de la crítica. Newman tiene la intención de explicar por qué es así. ${ }^{10}$ Para la exposición de tales motivos, voy a sintetizarlo en cinco argumentos:

\section{Argumento 1}

Es un hecho que el encanto de la tragedia griega no surge de la corrección científica de la trama. Si bien se dice que la acción es lo central, en lugar de ser progresiva y sostenida, en muchas ocasiones queda estacionada o irregular; por tanto, la acción es solo una condición necesaria del drama para introducir un elemento más importante que la misma acción. ${ }^{11}$

\section{Argumento 2}

Habitualmente, el mayor interés de una tragedia no se centra en la acción - que es lo que dice Aristóteles en la Poética- y la realidad es que la acción pasa a

\footnotetext{
${ }^{10}$ John Henry Newman, Ensayos criticos e históricos I, 2008, Madrid, Encuentro, edición y trad. de Gabriel Insausti, pp. 52-54.

${ }^{11}$ Ibid., p. 49.
}

ser una simple condición necesaria para introducir un elemento o personaje más importante que la misma acción. ${ }^{12}$

Argumento 3

"La acción entonces será más justamente considerada como el vehículo para la introducción de los personajes del drama, siendo éste el objeto principal del arte del poeta." ${ }^{13}$ Es decir, no está en la trama, sino en los personajes y sus sentimientos; en la dicción, que es el mérito real de la composición de la tragedia.

Argumento 4

El drama griego no fue modelado según principios científicos: era una recreación pura de la imaginación que revelaba su objeto o significado más allá de su propia exposición. "El mismo espíritu de la belleza respira a través de cada composición". ${ }^{14}$

Argumento 5

"Respecto a los principios, correctos o no, que siguen conduciendo a la excelencia", ${ }^{15}$ dice con atrevimiento que cuestiona incluso la suficiencia de las reglas de Aristóteles para la producción de dramas del más alto orden.

\footnotetext{
${ }^{12}$ Ibid., p. 52.

${ }^{13}$ Ibid., p. 50.

${ }^{14}$ Ibid., p. 51.

${ }^{15}$ Loc. cit.
} 
Pues el poeta no puede atender al mismo tiempo a la diligencia en la formación de la trama y a la espontaneidad de la imaginación.

\section{Segunda tesis}

Dice Newman que Aristóteles distingue entre el significado de "poesía" como el don y como la composición escrita, que es su resultado. Y afirma que no siempre ni todo lo escrito por alguien que tiene el don, resulta ser poético.

La poesía representa generalizaciones a partir del fenómeno de la naturaleza y de la vida, y proporciona cuadros dibujados, no según un patrón existente, sino después de una creación de la mente; es una ficción, le corresponde el hábil ajuste de las circunstancias para poner en evidencia la relación de causa y efecto en los acontecimientos narrados, con formas eternas de belleza y perfección seleccionadas del mundo físico o moral, utilizando el lenguaje metafórico para expresar a otros sus intensos sentimientos. "Los escritores ordinarios, por ejemplo, comparan a un anciano con un árbol en otoño; un poeta dotado reconocerá en los árboles sin hojas a los hombres sin más tiempo que vivir". ${ }^{16}$

\footnotetext{
${ }^{16}$ Ibid., p. 58.
}

\section{Tercera tesis: historia y poesía}

Aristóteles hace una comparación entre la historia y la poética. Por un lado, considera que la poesía es una representación del ideal, mientras que las biografías o historias representan personajes individuales y hechos reales, a lo que les corresponde la fidelidad a los hechos.

Newman comenta que el narrador histórico ha de discernir entre los hechos reales para elegir los relevantes e interrelacionados, mientras que el resto los omite. En cambio, una narración de ficción generaliza a partir de los hechos. El escritor extrae de la experiencia, de la misma manera que la pintura retrato, para ser poética, debe proporcionar una representación abstracta de un individuo, mostrando el espíritu general de su sujeto, independientemente de los accidentes de actitud, vestido o sentimientos ocasionales y transitorios. El artista logra recrear los hechos con el color de su imaginación poética. La elegancia de la simplicidad es también propia del talento poético: con elocuencia consumada, abre, ilustra y realza una idea hasta el final, antes de pasar a otra. Los temas de los que se vale el poeta son muy diversos: los hechos históricos, morales, naturales, psicológicos y hasta las reflexiones filosóficas pueden ser materia para la poesía. 
Cuarta tesis: lo que supone la originalidad del arte poético

La originalidad la define como el poder de abstraerse hacia uno mismo, de manera que esa fuerza de la mente se convierte en acción. Esta cualidad es posible en mentes que sienten una continua propensión a investigar a los sujetos y formar sus opiniones por sí mismas, de manera que aun lo que ha quedado establecido como verdad, es sometido a este proceso de "digestión mental". La capacidad de reflexión se convierte en un requisito indispensable para la originalidad; pero debe estar guiada por el buen gusto que conforma a la poesía, evitando la precipitación y la estridencia en la conducta exterior. La originalidad es energizante en el mundo de la belleza, es la gracia, la pureza, el refinamiento.

\section{Quinta tesis}

Newman considera que la poesía requiere la norma del carácter moral del escritor, y que de ello depende la excelencia poética de su obra. Se refiere a los principios morales en la mente del poeta, más que en la coherencia de su vida. Se enfoca en lo que hay en la mente del artista, porque de una mente viciosa su supuesta poesía resultará inconsistente y degradada, pues los cortos marcos mentales producen poesía parcial y limitada.

\section{Conclusiones}

El pensamiento de Newman goza de una gran unidad, como un cuerpo que va en crecimiento y perfeccionamiento, pero que desde muy pronto tiene líneas maestras. Este texto es una prueba. El joven Newman muestra cómo sentía ya la inquietud de discernir entre lo perfecto pero abstracto, formal, científico, y lo real, que finalmente es lo que tiene consistencia propia. Por ello, dice: "Si bien, el tratado de Aristóteles es del todo interesante y valioso, una cosa es construir el bello ideal de una tragedia con base en principios científicos, y otra señalar la belleza real de una escuela particular de composición dramática". ${ }^{17} \mathrm{E}$ insiste: "Los autores trágicos griegos generalmente no suelen acertar en la construcción de cada una de las partes de su obra". ${ }^{18}$

Así, Newman muestra su preocupación, por hacer notar la diferencia entre lo real concreto y lo que es producto de la mente. En este mismo tenor, la realidad es más rica y variada que la abstracción científica que ha

${ }^{17}$ Ibid., p. 49.

${ }^{18}$ Loc. cit. 
de tipificar y ha de intentar clasificar de manera estática. Ello reaparece en otras obras de corte filosófico como An essay in aid of a grammar of assent, The idea of a university, University sermons, Philosophical notebook.

En sus posteriores argumentaciones comenzará también por aludir en primer lugar a los hechos, que hablan por sí mismos. Así lo hizo en la Carta al Duque de Norfolk (1875), tomando como ejemplo de leal súbdito de la corona inglesa al católico al que dirigió esta carta. De esa manera, responde desde la primera línea al ataque de que tal caso no era posi- ble. Este escrito muestra un ágil manejo de la crítica literaria y la capacidad para ofrecer explicaciones que van más allá del texto mismo y deja entrever la pedagogía en la Universidad de Oxford en el siglo XIX.

Newman mismo fue un poeta, y sabía lo que supone tener ese don, que no siempre fluye igual. Es autor, por ejemplo, de un poema de 1000 versos titulado El sueño de Geroncio, al que Edward Elgar puso música para coro y orquesta. A manera de anécdota, tal habilidad podía fluir en él incluso mientras se afeitaba, y por ello muchas de sus composiciones poéticas quedaron sin escribir. 